\title{
The Use of Software Package and Commercial Catalogues in Development of Design Documentation
}

\section{Dr. Jorge Rodriguez P.E., Western Michigan University}

Faculty member in the Department of Engineering Design, Manufacturing, and Management Systems (EDMMS) at Western Michigan University's (WMU). Co-Director of the Center for Integrated Design (CID), and currently the college representative to the President's University-wide Sustainability Committee at WMU. Received his Ph.D. in Mechanical Engineering-Design from University of WisconsinMadison and received an MBA from Rutgers University. His B.S. degree was in Mechanical and Electrical Engineering at Monterrey Tech (ITESM-Monterrey Campus). Teaches courses in CAD/CAE, Mechanical Design, Finite Element Method and Optimization. His interest are in the area of product development, topology optimization, additive manufacturing, sustainable design, and biomechanics.

\section{Mr. Timothy Neil Thomas, CADENAS PARTsolutions LLC}

Tim Thomas is a founding partner and CEO of CADENAS PARTsolutions and continues to evangelize the importance of standardization techniques in design processes. Tim has 28 years of CAD technology development and application experience. Previously he spent thirteen years at Structural Dynamics Research Corporation (SDRC) where he was the Director of CAD Development. He was the COO at Computer Aided Systems for Engineering (CASE) where he was responsible for all aspects of the drafting software business until CASE was acquired by SDRC in 1998. Tim's career also includes working as a design engineer at Hughes Aircraft (now Raytheon), TRW (now Northrop Grumman) and Goodyear Atomic. Tim has a BS in Mechanical Engineering from Michigan Technological University where he served as Co-Chair of the Mechanical Engineering External Advisory Board, the Alumni Board, and is actively involved with STEM in the curriculum at many Universities. 


\title{
The Use of Software Package and Commercial Catalogues in Development of Product Design Documentation
}

\begin{abstract}
It can be stated that without a doubt the use of CAD/CAE systems in industry is ubiquitous nowadays. All graduates from technical careers are expected to have a working knowledge and skills on these engineering tools. The expectation at most industries is that designers will perform modeling and analysis tasks during their work. Unfortunately, a large portion of such work is repetition of work previously done, or it is basically repetitive work by the design person. The reutilization of existing work, or the utilization of commercially-available components, has not been emphasized in the curricula. This paper will describe the efforts that are being implemented in engineering design courses in order to address the idea of reutilization of work during the engineering design process.
\end{abstract}

Specific exercises have been developed in order to expose students on the tasks of using commercially available parts, reutilizing previous selected parts, and reutilizing previously designed parts. Teams of students are presented with these design exercises with the intention of having such concepts present in their minds as alternatives to explore. Initial results indicate a level of interest on the use of these techniques, and some suggestions have been presented as well for improvement of the materials used. It is expected that these concepts will bring an improvement in engineering design efficiency due to the fact that it is estimated that up to $45 \%$ of the parts currently specified in mechanical designs are commercially available components.

\section{Introduction}

Computer applications in the engineering and science fields are ubiquitous nowadays. The application of the computer in the engineering design process has evolved from the early CAD systems, as in Computer-Aided Drafting, from decades ago, to the CAD (as in Computer-Aided Design) that we have today. Even in new CAD has gone serious transformations based on the approaches for solid modeling that have been implemented, particularly moving from solid primitives to sketcher-based features. There have been a variety of developments and trends that have been proposed and implemented during this time. Some of them are the application of CAD techniques and results into Computer-Aided Engineering (CAE), and for the entire lifecycle of the product or system (PLM - Siemens 2015). One of the factors that has justified many of the existing trends and methodologies being currently used is the improvement of (engineering) design efficiency.

Studies indicate that there is a potential for significant reduction in design cycle time (up to $45 \%$, as stated in Thomas 2015) whenever reutilization of parts and models is carried out. Some data collected when a particular application was implemented in the industrial setting indicates that, even when there is an increase in the number of assemblies and version as the product matures, a reduction in the number of parts being utilized for such expansion is achieved (Figure 1). The use of parts libraries and catalogues has been proposed since the initial uses of CAD tools for drafting (Weisburg 2008). As well, even with the significant change to solid modeling and parametric 
technology, adaptation of techniques such as variational geometry have been implemented with the use of, among other characteristics, UDF (user-defined features) and family tables. These implementations are in support of the classical libraries and catalogues.

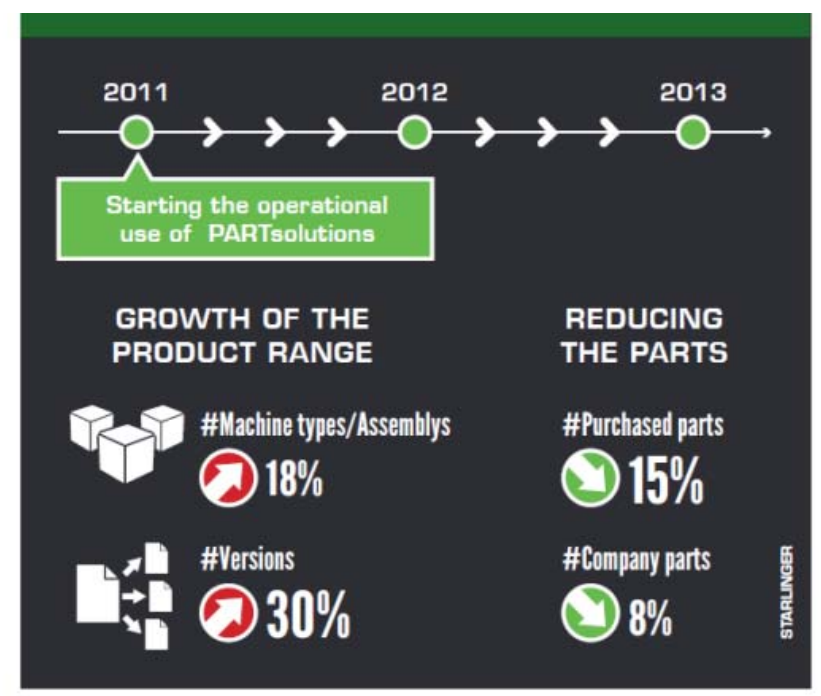

Figure 1. Realization of reduction in number of components as product versions increased.

More recently, the implementation of PLM (Product Lifecycle Management) in industry is as well another reason why there are software developers that offer packages that have the capability to reutilize designs and parts, e.g., PARTsolutions and Sconce. It is even more common to have engineering service bureaus offering services related to classification and reuse of parts and designs. It is a clear trend that supports the 3-R philosophy adopted at several industries, like Nissan, where they would Recycle-Reduce-Reuse. It can be said that this is a natural technological development that fits very well with the emphasis is sustainability that has been promoted at different levels and at different institutions, be that academic or otherwise.

Manufacturing and supplier industries have not been blind to such developments, even when their timing can be considered a bit off with respect to the need. These industries have released great improvements in recent times, partially due to competition and globalization. Several industries started providing 2D representations of their selected parts in order to be used in the final documentation of their designs. However, now the trend is to provide complete 3D models of candidate components, and furthermore, to provide the option to either configure their selection or to customize it.

This report describes the approach being implemented to expose students to the reutilization/ configuration concept in CAE. These efforts are in a design curriculum at an institution of higher education, and it is planned to expand from its current implementation in an introductory design course at the junior level. 


\section{Methodology}

The goal for the proposed implementation is to expose students to the concept of reuse in the engineering design process. In order to have emphasis on such concept, students will be given a set of demos and exercises that cover some of the main characteristics of the computer tool being used. It is important that this material is a complete departure from the activities performed previously where either, the designer downloads parts from a catalogue offered by the manufacturer, or the designer uses library parts already 'someplace' in its CAD system. The new tools are developments with PLM in mind and embedded into a CAD system. They have capabilities for classification, search, and reuse of parts and components, either from commercial catalogues or their own.

The course is at the junior level, in the 2-hours lecture and 3-hour lab per week format, and it is a required course in an engineering design program at a 4-year institution. The set of exercises are assignments for the lab portion of the course, and it consists of one demo/tutorial exercise and two assignment exercises. This set is given to the students as in-lab (demo/tutorial exercise) and as homework two (assignment exercises) in a 3-week period. The sequence is presented in Table I.

Table I. Proposed Activities for Introduction of Concept of Reutilization.

\begin{tabular}{|c|l|l|l|}
\hline & \multicolumn{1}{|c|}{ Week 1 } & \multicolumn{1}{c|}{ Week 2 } & \multicolumn{1}{c|}{ Week 3 } \\
\hline & Survey Pre1 & \multicolumn{1}{c|}{ Survey Post1 } & \multicolumn{1}{c|}{ Survey Post2 } \\
\hline In-lab & Demo exercise & Assignment 1 & Assignment 2 \\
\hline & Tutorial exercise & & \\
\hline Individual & Components T1 & & \\
\hline Team (E2) & Components T2 & Components 1-1 to 1-4 & Components 2-5 to 2-8 \\
\hline & & CAD work - Report A1 & CAD work - Report A2 \\
\hline Homework & & & \\
\hline Team(E3) & Assignment 1 & Assignment 2 & \\
\hline
\end{tabular}

For the first session the students are provided with introductory information about the computer tool to use (i.e., PARTsolutions), and then are given the demo on the use of the software. The demo illustrates the utilization of the software tool for the selection of different standard parts, mainly pneumatic piston and brackets. The tutorial exercise implies the reutilization of the demo components based on new specifications. The change in specifications are in terms of expected performance, with no geometric limitations. The results for these changes are provided as an individual's task, and the result for the assignment are discussed in teams in order to have additional discussion regarding the use of the software tool. Each team has two students during this in-lab assignment, and the task is selection of standard components out of the available catalogues in the software. 


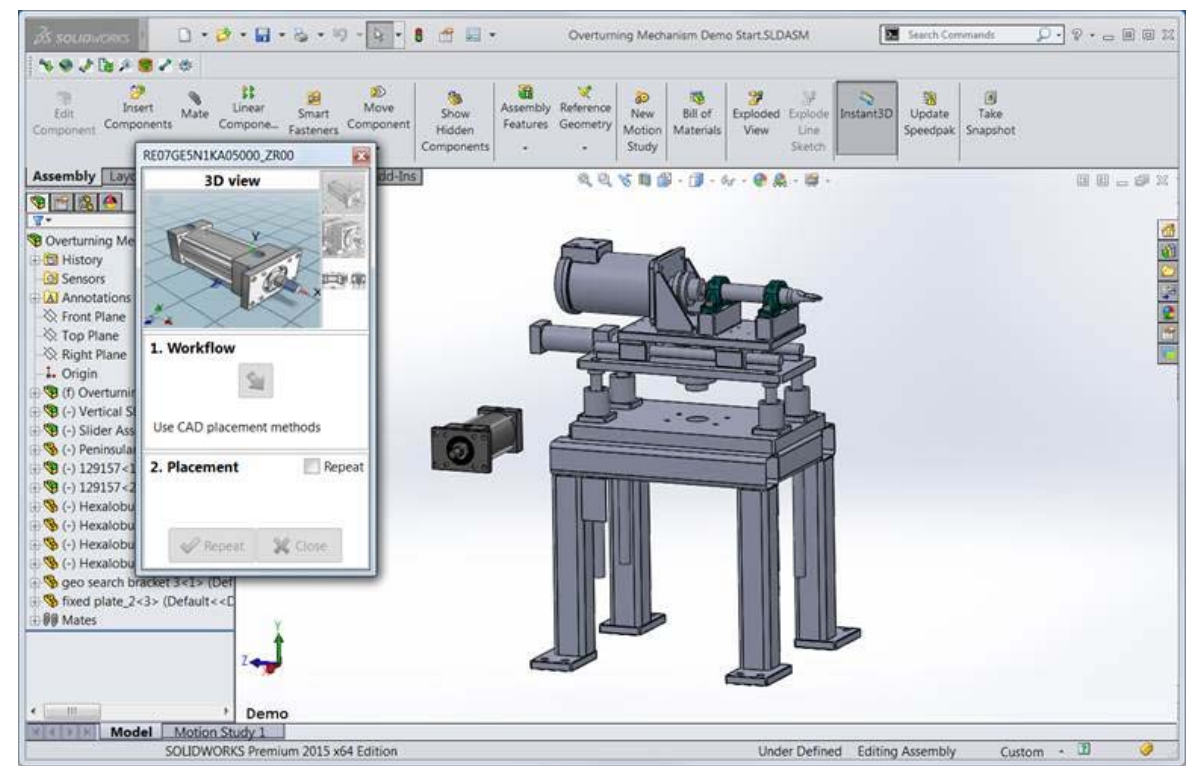

Figure 2. Screenshot Illustrating Placement of Pneumatic Component in CAD.

The assignment exercises are brand new problems. The first one requires the selection of four main standard components, and the second one includes at least eight components, with the requirement to modify standard components. Figure 2 illustrates the CAD work done for standard components. This second exercise (E2) implies design of additional components, but only some of them are based on reutilization or selection/configuration. The third exercise (E3) implies the use of some of the components designed by other teams in the previous exercise, in order to emphasize the search features. Search options in this tool include by geometry and by text. Figure 3 illustrates the parameters that describe a catalogue component, with the option to specify them according to design calculations. The commonality in these problems is automation with fluid power, and the specifications for each team are different, so that unique solutions are expected for each situation. These assignments are done in teams of three students, with each team submitting a report.

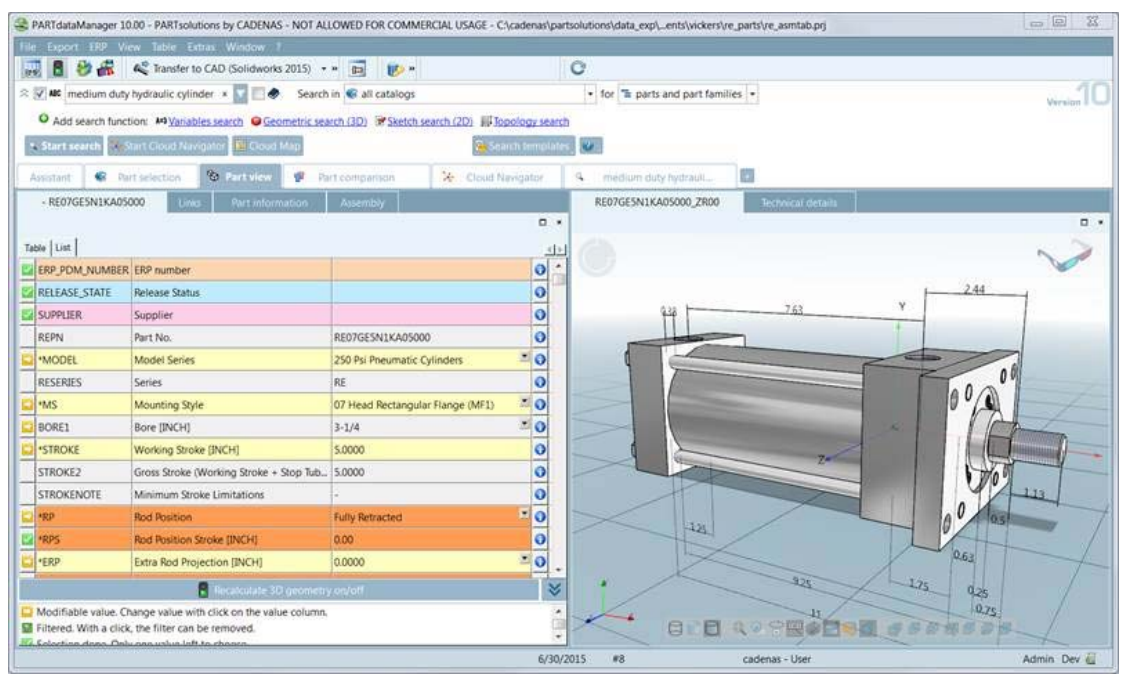

Figure 3. Screenshot Illustrating Specifications for Cylinder Based on Requirements. 
The first assignment problem is a 'positioning mechanism' that requires selection of source/control of power, linear actuator, and power transmission with emphasis on position. The second assignment is a 'pushing mechanism' that adds the need for a load-based device, with the expectation of some reutilization. The expected delivery at the end of the week-long project is the basic engineering of the proposed system, with specifications for the main components and CAD representation of the system.

\section{Evaluation}

The evaluation for this project is based on the objective of providing exposure to the concept of reutilization of parts and components in an engineering design process. The information will be collected with the use of surveys where students indicate their agreement or disagreement with respect to their knowledge and perception of the concept of reutilization, and the use of commercial catalogues. The survey is initially administered before the concept and tool are introduced, and then at the end of the academic tasks, basically a before and after.

The survey was an open one where students were asked to provide comments on the aspects that they liked and the ones that they did not, as well as some improvements that they felt would improve the overall experience - partially following the SWOT idea. One numerical question at the end ask them about the overall experience. Some of the comments received from students were:

Liked:

- Good exposure to real world workplace

- The ability to design something with existing parts

- The project or problem itself was interesting

Disliked:

- The time constraints

- Objective was vague

- Not being able to put a lot of time

Improvements:

- Less deadlines.

- Have this project at the beginning of the semester

- Have it be the only project

In terms of numerical evaluation, Table 2 below provides a summary. The results were based on 20 students, and the scale was a Likert scale from 0 to 5 , with 5 being the best score. The results indicate that there is a high level of expectation before the start of the exercises (i.e., average score of 4.28), which decreases after the set of activities (i.e., average score of 3.95). On the other hand, there is a wider spread at the start (i.e., standard deviation score of 1.59), perhaps in part due to the fact of students not knowing exactly the concept and material to be covered, but there was less spread (i.e., standard deviation score of 0.21) at the end of the exercises, perhaps due to their learning of commercial computer tools for definition, selection, and reuse of parts and components in engineering design. 
Table 2. Survey Results

\begin{tabular}{|l|c|c|}
\hline & Before & After \\
\hline & & \\
\hline Average & 4.28 & 3.95 \\
\hline & & \\
\hline $\begin{array}{l}\text { Standard } \\
\text { Deviation }\end{array}$ & 1.59 & 0.21 \\
\hline & & \\
\hline
\end{tabular}

The expectation is that this initial implementation results in positive trends in three main aspects: a) to place in the mind of the students the concept of reutilization, b) to introduce students to current computer tools that facilitate the design process, and c) to have the basis for improvement of the implemented set, at this level and at advanced levels.

\section{Conclusions}

The proposed set of assignments to introduce reutilization in design courses requires well linked concepts and exercises in order to focus the efforts on the goals. It is very easy to get into aspects that are not the focus of the task, such as software-use issues. Survey results are expected for this first offering on the materials, indicating that there is a positive aspect in the objective of presenting the concept of real-life reutilization to students. There are some good aspects, and as well there are several logistics aspects that need to be worked out. However, the concept is an important one that needs to be emphasized in consequent courses. The authors plan to improve on the initial implementation, and expand its use in subsequent courses. An interesting quote, which does not have the intention of being a marketing tactic, but it is important to rely to students is "The consequent use of the parts management system already enforces the reduction of part selection in the early stages of development" (Jurgens, 2016).

\section{References}

Juegens, Frank, Manager Standarization Department EES, MAN Truck \& Bus AG

PARTSolutions (2015). www. Partsolutions.com/products/

Siemens Product Lifecycle Management Software Inc. (2015). Teamcenter: Simplifying PLM.

Tim Thomas (2015). Parts Management 101 - A Primer of Engineering Standards Management. CEO PARTsolutions. Stated by Aberdeen Group.

Weisburg, David E., (2008). The Engineering Design Revolution. Chapter 2: A Brief History of CAD Systems. 